\title{
Suicide among elders: a Durkheimian proposal
}

\author{
By Stephen M. Marson* E Rasby Marlene Powell*
}

\begin{abstract}
This article proposes a model based on Durkheim's suicide framework as a tool for enhancing gerontological practitioner's ability to detect and prevent suicide among elders. Although many suicide detection tools are based on psychological factors, this model focuses on identifying environmental stressors that may increase psychological stressors. To illustrate our concepts, we use case files from one author's experience as a practicing social worker in nursing homes. We offer this model not as a replacement for psychological detection tools, but as an additional tool for practitioners who work to identify and prevent suicides among the elderly.
\end{abstract}

Keywords: Suicide, aging, Durkheim, suicide intervention.

\section{Introduction}

Although elderly suicide rates have been declining in the USA since 1987 (AAS 2011), suicide continues to be a major problem among elderly populations (Hooyman \& Kiyak 2011). Unfortunately, there is a long

*Stephen M. Marson and Rasby Marlene Powell, Sociology Department, University of North Carolina, Pembroke, USA 
International Journal of Ageing and Later Life

history of this phenomenon. In fact, Lorand (1912) called this problem to our attention 100 years ago. According to the National Institute of Mental Health, elderly persons are more likely to die from suicide than any other age group. The American Association of Suicidology (2011) claims that an elderly person died from suicide every 100 minutes in the USA in 2005 and every 97 minutes in 2007 . While $12.5 \%$ of the US population is elderly, $15.7 \%$ of all suicides are among the elderly (AAS 2011). During 2007, the suicide rate for all persons 65 and over was 14.3 per 100,000 and 31.1 per 100,000 for White males (AAS 2011). Elderly White males aged 85 and older are at even greater risk with rates of 45.42 per 100,000. During 2004, for example, the suicide rate for White males aged 85 and older was four times higher than the general population (NIMH 2011). One factor that may contribute to the difference is that $92 \%$ of elderly men commit suicide with firearms as compared to $8 \%$ of elderly women (AAS 2011). See (Figure 1).

The problem of elderly suicide is not restricted geographically. International data presented by De Leo and Spathonis (2004) demonstrate that elders around the world have higher suicide rates than other age groups.

Figure 1. Suicide rates per 100,000 population.

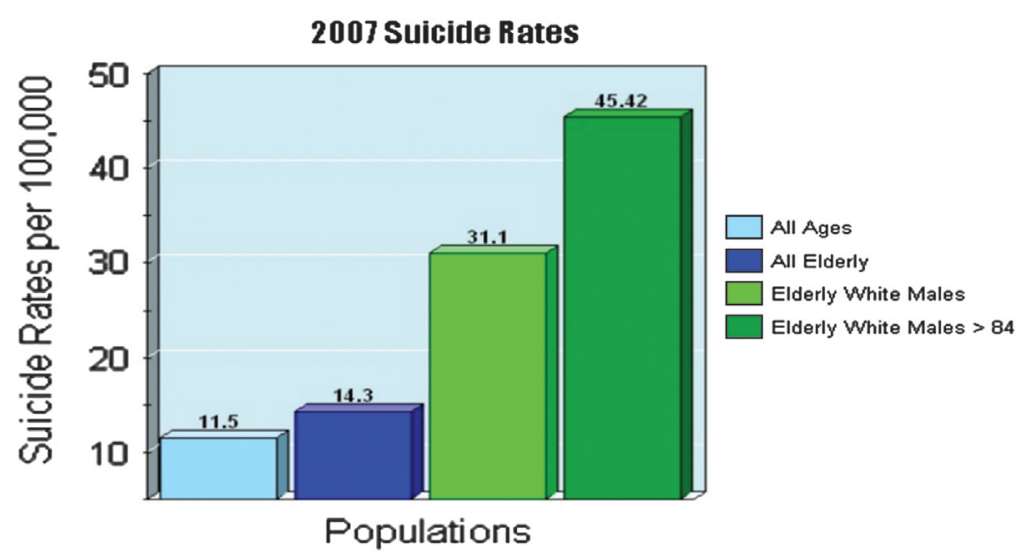


We call attention to the fact that both national and international descriptive statistics often fail to consider passive suicide in the statistics. Active suicide occurs when persons purposely kill themselves through their actions. Passive suicide occurs when a person refuses to take the necessary measures to remain alive such as refusing lifesaving medical treatments or food and water. According to Durkheim (1897: 42):

\footnotetext{
Though suicide is commonly conceived as a positive, violent action involving some muscular energy, it may happen that a purely negative attitude or mere abstention will have the same consequence. Refusal to take food is as suicidal as self-destruction by a dagger or fire-arm.
}

Thus, we contend that current figures underestimate actual suicides among the elderly. In this report, we treat active and passive suicide as equally problematic in terms of identification and prevention.

Many introductory gerontology textbooks rely solely on psychological theories to explain elderly suicide trends (Hooyman \& Kiyak 2011; McInnisDittrich 2009; Quadagno 2011). A typical representation of psychological explanations is that of McInnis-Dittrich's (2009) that offers a typology of depression to help practitioners identify various depressive states that may lead to suicide:

- Reactive depression - mild depressions that arise as a result of a loss or accumulations of losses.

- Clinical depression - out of proportion to the cause with symptoms that persist beyond the usual time and interfere with normal functioning.

- Endogenous depression - a state of deep melancholy unrelated to an obvious cause, which may be more severe and more frequent as they grow older.

- Involutional depression - associated with life-span problems and biological deterioration during the middle years that may be reactivated in old age.

Although this typology offers good insight as to the differences in types of depression, psychology texts offer the practitioner little guidance in constructing practical interventions. We argue that the sociological model 
International Journal of Ageing and Later Life

we propose provides an additional tool to help practitioners identify and prevent suicides. Without diminishing the importance of being able to identify changes in emotional states, we argue that many psychological problems are linked to changes in structural arrangements. Thus, we offer a model to help practitioners identify changes in structure that can lead to changes in emotion. Although we acknowledge that no single theory or model is likely to completely solve the problem of elderly suicide identification and prevention, we contend that Durkheim's theory of suicide provides additional clarity and much needed insights that can shelp the practitioners in their mission to provide quality care.

Durkheim's (1897) suicide theory has had a major influence on those who study and attempt to prevent suicide but, as noted within major gerontological textbooks, very little of his work has informed the service delivery arena of aging. Durkheim (1897) asserted that suicide cannot be explained adequately by psychological factors alone. Instead, he argued that several structural issues can give us a better understanding of the psychological factors linked to suicide. He provided empirical evidence to support his claims. Although not all agree (Nolan \& Triplett 2010), we see replication studies which illustrate that Durkheim's theory remains as relevant today as it was then (Baller et al. 2010; Classen \& Dunn 2010; Davenport \& Davenport 1987; Helmut 2010; Maimon et al. 2010).

Durkheim (1897) proposed four types of suicide related to structural factors. These include anomic, fatalistic, egoistic, and altruistic. After defining the various types, we present each type in terms of its relevance for understanding self-destructive behavior among elderly in the USA. Finally, we present a model for using Durkheim's theory in practitioner settings.

\section{Structural Factors and Types of Suicide}

Durkheim (1897) found that two structural factors affected suicide rates: level of regulation and level of integration. He found that when a group or culture had too little regulation or too much regulation, the suicide rates increased. For example, Durkheim claimed that well-functioning societies have norms, traditions, laws, and other sorts of regulations that guide our daily lives. During rapid social change, the "regulative force" of norms and 
traditions often becomes chaotic, leaving people with a feeling of anomie, a sense of normlessness, and rootlessness. Durkheim (1897: 258) claimed that "in anomic suicide, society's influence is lacking in the basically individual passions, thus leaving them without a check-rein." On the other hand, when regulations take over one's life, we develop a sense of fatalism and hopelessness. Durkheim (1897: 276) claimed that this leads to " ... the suicide deriving from excessive regulation, that of persons with futures pitilessly blocked and passions violently chocked by excessive discipline ... we might call it fatalistic suicide." Too much or too little social integration also affects suicide rates. When people have too little social integration, they tend to be self-focused and disconnected from others. This can result in people feeling as though no one cares whether they live or die. On the other hand, people who are too integrated may willingly give their own life in the attempt to benefit the life or lives of others:

Having given the name of egoism to the state of the ego living its own life and obeying itself alone, that of altruism adequately expresses the opposite state, where the ego is not its own property, where it is blended with something not itself, where the goal of conduct is exterior to itself, that is, in one of the groups in which it participates. (Durkheim 1897: 221)

Thus, Durkheim grounded his suicide typology on the following continuums of regulation and integration:

- Anomic suicide: more likely when level of regulation is too low.

- Fatalistic suicide: more likely when level of regulation is too high.

- Egoistic suicide: more likely when level of group integration is too low.

- Altruistic suicide: more likely when level of group integration is too high.

According to Durkheim, the state of low social regulations that occur with rapid social change often result in feelings of normlessness and rootlessness that can lead to anomic suicide. For example, after the break up of the Soviet Union, suicide rates increased as people struggled with rapid deregulation (Pridemore et al. 2007). On the other hand, living under harsh 
International Journal of Ageing and Later Life

dictatorships or other conditions of excessive regulations where there is no hope for positive change can lead to fatalistic suicide. Aliverdinia and Pridemore (2007) found that Iranian women who live in hyperregulated regions of Iran commit suicide at greater rates than Iranian women who are subjected to less stringent regulations. Durkheim claimed that unhealthy levels of integration can also lead to suicide. A recent study that corroborates his claim is Brown and Day's (2008) finding that prisoners who have no social support systems are at higher risk for egoistic suicide than those who are not as lonely. In contrast, Palestinian suicide bombers provide examples of excessive group integration (Pedahzur \& Perliger 2003).

\section{Using Durkheim's Theory to Help Practitioners}

We offer a conceptual model for using Durkheim's (1897) theory to help practitioners identify suicidal risks so that they can intervene more successfully. Our model relies on Durkheim's (1897) concept of regulation and integration continuums. Figure 2 illustrates the relative continua of regulation and integration. The figure also illustrates that the danger zones can overlap one another.

This diagram illustrates that the vertical and horizontal axes cross in what we label as a safety zone. As long as levels of both regulation and integration remain within the safety zone and outside the danger zone, the incidence of suicide should be low. In other words, elderly persons who are aware of and feel comfortable with the amount and type of regulations that guide their daily lives, and those who are appropriately connected to others, will be in a safety zone. However, if a person begins to move out of the safety zone and into the danger zone on either axis, the probability of suicide increases. Moreover, if a person moves out of the safety zone on both axes, the probability of suicide becomes even more prevalent. Moreover, the diagram illustrates that a person may move into danger on a single axis or on two axes simultaneously. For example, a person may experience high regulation and low integration at the same time. Likewise, high regulation may intersect with high integration, and so on. 
Suicide among elders

Figure 2. Durkheim's suicide model.

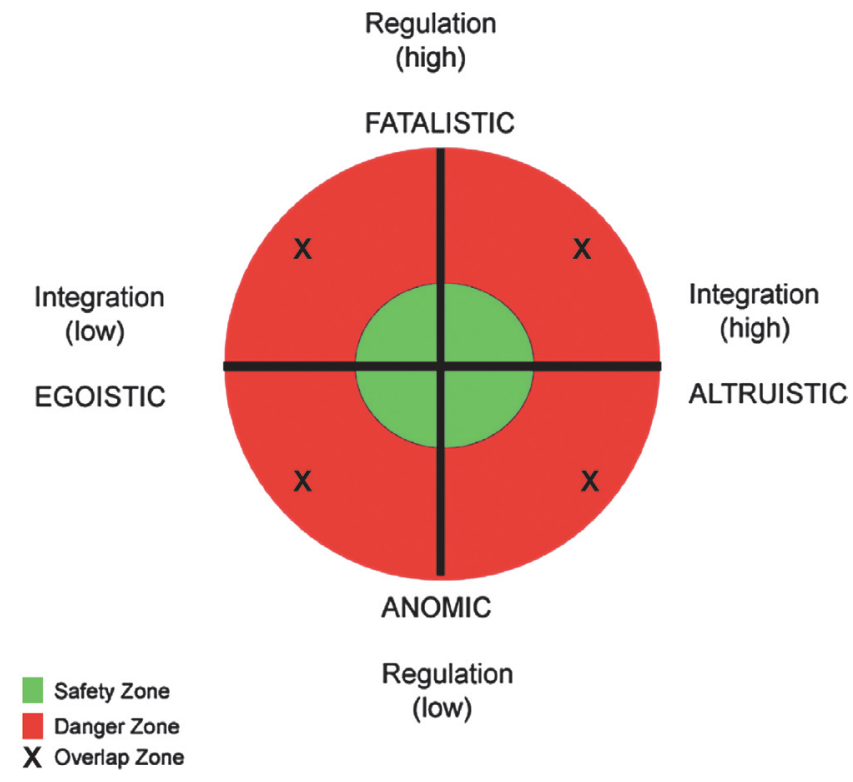

\section{Anomic Suicide}

On the Regulation continuum in Figure 2, elderly persons who have spent their lives working and accomplishing goals often find the sudden normlessness of retirement to be disconcerting. Without the regulation of earning and living elders may flounder and feel anomic as they struggle to figure out what to do with themselves. The following case study illustrates this situation ${ }^{1}$ :

\footnotetext{
${ }^{1}$ The case studies in this article are from one of the author's private case files collected as a practicing social worker in nursing homes. They are used only to illustrate concepts. All names have been changed to protect the privacy of clients.
} 
International Journal of Ageing and Later Life

\begin{abstract}
Mrs. Jones (age 69) raised one child and worked full time as a highly skilled accountant. She consistently earned more than her husband and, although her life was very busy, she was able to maintain a high level of productivity both at home and work because she had set routines to guide her time. She had looked forward to retirement with great anticipation and was shocked at how bored she was with the lack of mental activity and normative routines. Within two weeks, she was so bored at the sudden changes that she lapsed into what Durkheim would label as anomie.
\end{abstract}

A psychiatric assessment of Mrs. Jones' condition would likely result in a diagnosis of "reactive depression" (see the aforementioned McInnisDittrich model). A probable treatment protocol would be to subscribe a mild antidepressant. However, according to Durkheim's (1897) theory, the underlying problem would not be solved. Drugs can be an important treatment to help with symptoms, but they do not solve the structural problems that result in Mrs. Jones' anomie. According to Durkheim's (1897) model, the rapid change in the level of regulation would be a likely cause of the problem and may have moved Mrs. Jones into the danger zone. Thus, to intervene, a practitioner may want to consider ways to restore an adequate level of regulation to Mrs. Jones' life. For example, it may be helpful to set up some routine activities that would give order and provide routines. Mrs. Jones may be able to volunteer her accounting services or join a regular exercise class. These sorts of routine activities can regulate the day and restore a sense of normality.

\title{
Fatalistic Suicide
}

Many of the issues faced by the elderly put them at risk of moving into the danger zone. For example, Hawgood et al. (2004) noted that the association between physical illness and suicide has been well documented since 1928, but they do not place their observations within a theoretical framework. We contend that chronic or very painful illness may move people toward a fatalistic risk situation. Their lives are regulated by an illness over which they have no or very little control. There is little they can do to change their situations. They have little to look forward to except more of the same day-to-day misery. In addition to chronic illnesses, the elderly may also feel fatalistic when they have little control over their 
living conditions and day-to-day lives, such as when they are forced by financial reasons to give up their homes and independence.

The concept of fatalistic suicide may be useful in understanding and intervening in what has been labeled as passive suicide (Marson 2009). One environment that provides fertile ground for the investigation of passive suicides is nursing homes (Cohen-Mansfield et al. 1995; Lee et al. 2009). Nursing homes as well as other institutions that provide 24 hour human/health services must rely on routines and schedules (Gage et al. 2009). Without schedules and routines, even the most efficient and wellmeaning staff members would be unable to meet the regulatory demands of the institution. Nursing homes with greater funding can inject greater variety into residents' schedules (Benjamin et al. 2009). Thus, underfunded nursing homes and for-profit nursing homes are the most likely to have rigid schedules (Goodson et al. 2008; Mitka 2009). These highly regulated settings increase the risk for fatalistic suicides. Mrs. Jones' case is a good example of this:

\begin{abstract}
Six months after her husband's death, Mrs. Jones-who was already suffering from depression-fell and cracked her head and broke her hip. She struggled for an hour just to call 911. While being lifted by the medics, Mrs. Jones lost control of her bowels and soiled herself. Six months later, in a for-profit nursing home, Mrs. Jones was misdiagnosed as senile with encopresis. ${ }^{2}$ Although initially, Mrs. Jones was profoundly humiliated with her soiling, she rapidly evolved into a patient who no longer cared about her personal hygiene or health.
\end{abstract}

Through a series of random social and health events, Mrs. Jones found herself confined to a nursing home where her life was highly regulated and out of her control. Because of her misdiagnosis, any sort of active intervention is a low priority for the overworked staff. Mrs. Jones committed passive suicide by retreating into her mind, refusing to eat, and willing herself to die. When practitioners identify that a patient has moved into the fatalistic zone, they can alert the patient's doctor to determine if psychiatric treatment is needed. They can also alert family members who may be able to help the patient feel less fatalistic.

\footnotetext{
${ }^{2}$ Inability to control one's bowels. For elderly patients, the origin is usually identified as psychiatric (anxiety) or the result of dementia.
} 
International Journal of Ageing and Later Life

Mrs. Jones' scenarios provide excellent examples of how a person's social environment can switch from one end of a continuum to another fairly rapidly. First, her retirement caused feelings of anomie as she struggled to figure out what to do with herself. Then, a series of health problems that resulted in confinement to a nursing home where her days were rigidly regulated moved her quickly into the fatalistic zone. This type of rapid movement from one danger zone to another may increase suicidal tendencies. Not only can patients move from one end of a continuum to the other, but they may also be in the danger zones of both regulation and integration at the same time. This results in double red zone outcomes (see Figure 2 for intersection points). Durkheim's four concepts are not discrete entities but are relative. In addition, although Durkheim's concepts are best described as independent, they can exist simultaneously in a single social environment.

\section{Egoistic Suicide}

The elderly must face many other issues that also affect their level of integration. For example, the death of friends, spouses, and family members can cause the elderly to feel less integrated into their communities. Moreover, many seniors lose connections when they are forced either by health or financial concerns to move away from familiar surroundings to nursing homes or into family members' homes. Some lose connections when they move into retirement centers that promise a grand new life only to find that they are very lonely without their families and friends nearby. As their feelings of connections decrease, their risk of egoistic suicide increases. When the elderly disengage from individuals or groups that provide social connections, they increase the risk of moving into the Egoistic Danger Zone. Unfortunately, researchers have documented that the social and family ties that enable people to stay socially integrated often weaken or disintegrate as people age (Marson \& Della Fave 1994; Putnam 2000; Sarkisian \& Gerstel 2008; Thompson 1999).

One structural factor that increases the probability that the elderly will move into the Egoistic Danger Zone is that younger people have a tendency to avoid the elderly (Bousfield 2010; Widrick 2010). Although avoidance of the elderly is common in general (Mulder 1987), it remains less common within the family setting. Grandchildren rarely shy away 
from grandparents-unless the grandparents suffer from a debilitating medical illness. Medical problems can create a social cleavage between generations and within families. For example, hearing loss (presbycusis ${ }^{3}$ in particular) often creates barriers to communication and, thus, leads to social disengagement between the elderly and younger populations (Cienkowski 2003; Patten \& Piercy 1989). Few people, regardless of age, have the patience to constantly respond to: "What did you say?" As hearing loss and presbycusis limits people's ability to engage in conversations (Stuen 2006) because they can only hear parts of words and sentences, they often fake their understanding of a conversation. Consequently, their inappropriate responses project an image of senility (Kampfe \& Smith 1999). These sorts of misperceptions increase the likelihood that fewer and fewer people will try to maintain connections with an elderly person who suffers from hearing loss:

\begin{abstract}
During World War II, Mrs. Blumenstein contributed to the war effort by gaining employment in a roller bearing factory. She and her husband reared two sons. Mr. Blumenstein encouraged both boys to join the military upon reaching maturity. Their oldest son was killed in the Korean War. Their second son was killed in Viet Nam. Working in a factory for many years caused Mrs. Blumenstein to experience premature presbycusis. After the death of their sons, Mr. Blumenstein descended into depression and isolated himself from his wife, friends, and family. A profound and unrelenting sadness permeated their relationship. Because neighbors misidentified Mrs. Blumenstein's presbycusis as senility and avoided her, she was surrounded by people but isolated from all of them. Because she was highly aware of her surroundings, she lived a life filled with despair.
\end{abstract}

Mrs. Blumenstein's social isolation placed her firmly in the Egoistic Danger Zone. Although practitioners cannot force people to visit the elderly, they can help the patient feel more connected by talking to them about daily news events or other non-health-related topics as they carry out their routine tasks. Even if the patient does not answer, it may help them feel more connected to know that someone cares enough to keep them abreast of daily life.

\footnotetext{
${ }^{3}$ A lessening of hearing acuteness resulting from degenerative changes in the ear that occur especially in old age.
} 
International Journal of Ageing and Later Life

\section{Altruistic Suicide}

On the other hand, some elderly people feel so connected to their children that they commit altruistic suicide so that the cost of their care will not cut into their children's inheritances. For example, one man's father was diagnosed with inoperable cancer and killed himself so that his treatment would not bankrupt the family:

Jack's father left a note saying that he loved his family too much to put them through the agony and expense of watching him die a slow, painful, and costly death and hanged himself.

Cancer may move elders into the Fatalistic Danger Zone because of unrelenting pain. For example, Robinson and colleagues (2009) found higher suicide rates among elder cancer patients with a poor prognosis. On the other hand, the possibility exists that they may move into the Altruistic Danger Zone as they consider the consequences of their illness on their families. Wilson et al. (2005: 120) found that elders who perceive themselves a burden on their families are more likely to have an "active wish to die." Many cancer patients are fully aware of the drain on their family's emotional and financial well-being. Another case illustrates that, while not normative, altruistic suicide is not uncommon:

Mr. Pazonno was diagnosed with terminal pancreatic cancer with a life expectancy of 6 months. The medical care during this timeframe would severely drain his estate. As a result, he planned a way to hasten his death so his adult children would not be deprived of an estate he had worked all of his life to accumulate.

According to Leighton and Hughes (1955), altruistic suicide was more common among certain groups in the past than it is now. For example, the elderly of certain tribes and groups, such as the Eskimos, would end their own lives when they became a drain on the group. However, Leighton and Hughes (1955) found little evidence of altruistic suicides among Eskimos over the last century.

At the same time, rhetoric within the political arena suggests that the topic currently is on people's minds. During the Obama health care debate, politicians spoke of death panels that would encourage elders to end their lives prematurely in order to allow the estate to be inherited for 
the benefit of their children. Although political debates do not necessarily represent actual scenarios, we find it interesting that this debate has emerged in these financially troubled times. Although altruistic suicide rates seem to lag behind the other types of suicides in Durkheim's typology, we do find evidence that altruism exists while elders are living. Several studies find that the elderly will transfer their estate to their children and grandchildren in an altruistic attempt to avoid probate issues for their families (Lee et al. 2006; Ploeg et al. 2004). As we contend that many passive suicides are not counted in the suicide statistics, we have no reliable statistics on suicides that may prompted by altruism. When a practitioner suspects that a patient is in the altruistic danger zone, he or she can alert the patient's doctor and family members so as to determine whether psychological counseling may be helpful.

\section{Practical Application of Durkheim's Typology}

The problem with using any typology is the tendency to become theoretically inflexible. We must stress that the concepts of regulation and integration exist on a continuum, and in everyday life, a person can very quickly move from one position on the continuum to another. For example, the sudden loss of regulation in the form of routines and schedules experienced at retirement can quickly be replaced by very high levels of regulation resulting from an illness requiring institutionalization. Additionally, people can be in the danger zone on two continuums at the same time. An example would be a person who was institutionalized for a chronic health problem and, as a result, lost touch with friends and family. That person could move into the fatalistic and the egoistic danger zone simultaneously.

\section{Strategies for Identifying and Preventing Suicides}

Traditionally, practitioners have assessed suicide potential by examining depression. For example, Nezu et al. (2000) presented 94 different measurements for depression. Essentially, these measurement tools quantify psychological states or feelings. This citation provides the practitioner with a wide range of measures to demonstrate that a person is feeling bad 
International Journal of Ageing and Later Life

but includes little guidance for producing a positive change. On the other hand, Robinson et al. (1991) presented social measurement tools that assess the degree of anomie, egotistic, and altruistic patterns. These tools differ from psychological measurement tools in that they focus on environmental measurements.

Three major problems exist with the work of Robinson et al. (1991). First, they offer no measurement tool for Fatalistic patterns. The lack of an instrument is due to inadequate supporting data in Durkheim's (1897) original study. Today, a substantial body of data supports the existence of Fatalistic patterns within elderly populations (Bennett \& Collins 2001; Draper et al. 2002; Marson 2009; Suominen et al. 2003). Second, each measurement tool addresses only one dimension. Among the elderly, it is common to find multidimensional patterns resulting from inadequate regulation and integration. Successful intervention requires a measurement that addresses the multidimensional aspects of the problem. Third, none of the instruments include a line of demarcation that separates a social environment's safety zone from the danger zone. Currently, a research team is attempting to construct a measurement that includes all four dimensions of Durkheim's model that will eventually quantify an environment's threshold to the danger zone. Estimates suggest that it will take 5 years for a tool to be ready for practitioners. In the meantime, we provide some guidelines and a checklist to help practitioners identify when an elderly person is moving into the danger zone.

\section{Identifying and Preventing Fatalistic/Anomic Suicides}

What strategies can a practitioner employ to prevent an elderly person from moving into the danger zones on the Fatalistic/Anomic continuum? First, care must be taken to provide enough regulation so that life has a predictable routine. When retirement or the death of a spouse suddenly dismantles life-long routines, a person can quickly become anomic and feel like there is nothing to guide their day. All of us, including the elderly, need a semblance of routine so that we can feel rooted in our lives. At the same time, too much regulation causes people to lose hope that they will have any way of ever regaining any kind of control over their own life. This means that practitioners must be cognizant of the fact 
that simply establishing routines and forcing their clients into them will do as much damage as not providing routines at all. To stay in the safety zone means that the person needs routines, but they also need to feel as though they have some control over those routines so as not to fall into fatalistic danger zone. The following checklist may help practitioners identify when elders are moving into danger zone on the Anomic/Fatalistic continuum.

\section{Anomic}

- Have life-long routines suddenly changed because of retirement, deaths of loved ones, or changes in living situation?

- Has the person recently moved from a position of authority to a position of dependence?

- Has the person adapted to changing social norms and technologies or do they spend their time feeling nostalgic for the past?

\section{Fatalistic}

- Does the person live in a nursing home that has a history of deficiencies during audits?

- Does the person express hopelessness about their future?

- Does the person have a chronic or acute medical condition for which there is no cure?

- Does the person have presbycusis (loss of hearing)?

\section{Identifying and Preventing Egoistic/Altruistic Suicides}

Helping clients stay in the safety zone on the Egoistic/Altruistic continuum necessitates focusing on social connections. Keeping in mind that numbers of contacts, alone, do not guarantee connections, care must be taken to focus on social integration rather than simple social interaction. Elders need opportunities to form connections that will help them stay connected to the social world. Complaints about loneliness or feeling left out may indicate egoism. Many times, hobby groups or church involvement helps the elderly maintain connections. If they are physically able, volunteer 
International Journal of Ageing and Later Life

work often connects the elderly to the outside world and helps them build and maintain connections. On the other hand, talk of draining children's inheritances or being too much of a burden on their families often signals what Joiner (2005) referred to as perceived burdensomeness and could indicate that the person is moving into the Altruistic Danger Zone. This danger zone lends itself to passive suicides. Additionally, complaints of this nature can easily be overlooked unless one is familiar with the notion of altruistic suicide. The following questions help identify movement toward the Egoistic/Altruistic danger zone.

\section{Egotistic}

- Does the person actively shun visitors or staff?

- Does the person usually eat meals alone or avoid social activities?

- Do children and other family members fail to call or visit?

- Does the person have no friends who visit or friends within the nursing home?

\section{Altruistic}

- Does the person have a history of providing economic assistance to family members or significant others?

- Does the person's sense of identity revolve around being the one people can count on, the one who takes care of others?

- Does the person speak of leaving their children an inheritance on a regular basis?

- Do social bonds between the person and family appear to be excessively strong?

- Is the person fearful of being a burden on their families?

\section{Discussion}

Durkheim's (1897) suicide model provides an important tool for practitioners because it allows us to develop guidelines that can be employed to reduce the probability of active and passive suicide. A review of the 
literature on practice strategies for prevention and prediction of suicide illustrates that the target of intervention tends to focus on the individual psyche. The basic strategy focuses on changing the person's mental vision (i.e. self-esteem) through psychotherapy or their mood with psychotropic medications. Although we agree that these methods are sometimes wholly appropriate, Durkheim's (1897) model for intervention focuses on structural issues that can cause loss of esteem and depression. His model illustrated that levels of regulation and integration greatly impact the probability of suicide. Thus, we are suggesting a method of practice that is contrary to most training programs in human and medical services. We contend that practitioners should consider the macro issues that can, in turn, reduce or eliminate micro problems. We also claim that simply trying to treat the individual without changing the structural environment decreases the chance of successful intervention.

Although we make no claims that our model will prevent all elderly suicides, it will serve to assist practitioners in identifying factors that influence an elder's decisions to commit suicide. Additionally, it may assist practitioners to identify the root of the depression, thereby increasing the probability that depression can be successfully treated. If practitioners have better tools to recognize when a person begins moving into a danger zone, they will have a better change of employing successful interventions.

\section{Acknowledgements}

An earlier version of this article was presented at the $32^{\text {nd }}$ Annual Meeting of the Southern Gerontological Society, Raleigh, NC, USA, April 16, 2011.

\section{Corresponding Author}

Stephen M. Marson, Sociology Department, University of North Carolina, Pembroke, NC 28372, USA. Email: steve.marson@nc.rr.com

\section{References}

AAS (American Association of Suicidology) (2011) Elderly Suicide Fact Sheet. Available on www.suicidology.org. (Accessed: August 12, 2011). 
International Journal of Ageing and Later Life

Aliverdinia, A. \& Pridemore, W. (2009). Violence against women in Iran: A partial test of Durkheim in an Islamic Republic. Violence Against Women 15(3): 307-320.

Baller, R. D., Levchak, P. \& Schultz, M. (2010). The great transformation and suicide: Local and long-lasting effects of 1930 bank suspensions. Suicide and Life-Threatening Behavior 40(6): 574-586.

Benjamin, K., Edwards, N. \& Caswell, W. (2009). Factors influencing the physical activity of older adultus in long-term care: Administrators' perspective. Journal of Aging and Physical Activity 17(2): 181-195.

Bennett, A. T. \& Collins, K. A. (2001). Elderly suicide: A 10-year retrospective study. American Journal of Forensic Medicine and Pathology 22(2): 169-172.

Bousfield, C. (2010). Contact, anxiety, and young people's attitudes and behavioral intentions towards the elderly. Educational Gerontology 36(6): 451-466.

Brown, S. \& Day, A. (2008). The role of loneliness in suicide prevention and management. Journal of Offender Rehabilitation 47(4): 433-449.

Cienkowski, K. M. (2003). Auditory aging: A look at hearing loss in older adults. Hearing Loss: the Journal of Self Help for Hard of Hearing People 24(1): $12-15$.

Classen, T.J. \& Dunn, R. A. (2010). The politics of hope and despair: The effect of presidential election outcomes on suicide rates. Social Science Quarterly 91(3): 593-612.

Cohen-Mansfield, J., Werner, P., Weinfield, M., Braun, J., Kraft, G., Gerber, B. \& Willens, S. (1995). Autonomy for nursing home residents: The role of regulations. Behavioral Sciences and the Law 13(4): 415-423.

Davenport, J. A. \& Davenport, J. (1987). Native American suicide: A Durkheiman analysis. Social Casework 68(2): 533-539.

De Leo, D. \& Spathonis, K. (2004). Suicide and suicidal behaviour in latelife $\left(1^{\text {st }}\right.$ edition). In D. De Leo, U. Bille-Brahe \& A. Kerkhof (eds.), Suicidal Behaviour: Theories and Research Findings (pp. 253-286). Cambridge, MA: Hogrefe \& Huber.

Draper, B., Brodaty, H., Low, L., Richards, V., Paton, H. \& Lie, D. (2002). Self-destructive behaviors in nursing home residents. Journal of the American Geriatrics Society 50(2): 354-358.

Durkheim, E. (1897). Suicide: A Study of Sociology. New York: Free Press. 
Gage, H., Knibb, W., Evans, J., Williams, P. \& Rickman, N. (2009). Why are some care homes better than others? An empirical study of the factors associated with quality of care for older people in residential homes in Surrey, England. Health and Social Care in the Community 17(6): 599-609.

Goodson, J., Wooseung, J. \& Rantz, M. (2008). Nursing home care quality: Insights from a Bayesian network approach. Gerontologist 48(3): 338-348.

Hawgood, J., Spathonis, K. \& De Leo, D. (2004). Physical illness and suicidal behaviour ( $1^{\text {st }}$ edition). In D. De Leo, U. Bille-Brahe \& A. Kerkhof (eds.), Suicidal Behaviour: Theories and Research Findings (pp. 139-163). Cambridge, MA: Hogrefe \& Huber.

Helmut, T. (2010). Violent crime (and suicide) in imperial Germany, 1883 1902: Quantitative analyses and a Durkheimian interpretation. International Criminal Justice Review 20(1): 5-34.

Hooyman, N. \& Kiyak, H. (2011). Social Gerontology: A Multidisciplinary Perspective. Boston: Prentice-Hall.

Joiner, T. (2005). Why People Die by Suicide. Cambridge, MA: University of Harvard Press.

Kampfe, C. M. \& Smith, S. M. (1999). Late-onset hearing loss: Strategies for effective counseling. Adultspan Journal 1(1): 32-48.

Lee, R. H., Bott, M. J., Gajewski, B. \& Taunton, R. L. (2009). Modeling efficiency at the process level: An examination of the care planning process in nursing homes. Health Services Research 44(1): 15-31.

Lee, J., Kim, H. \& Tanenbaum, S. (2006). Medicaid and family wealth transfer. Gerontologist 46(1): 6-13.

Leighton, A.H. \& Hughes, C. C. (1955). Notes on Eskimo Patterns of Suicide. Southwestern Journal of Anthropology 11(4): 327-338.

Lorand, A. (1912). Old Age Deferred. Philadelphia, PA: F.A, Davis.

Maimon, D., Browning, C. R. \& Brooks-Gunn, J. (2010). Collective efficacy, family attachment, and urban adolescent suicide attempts. Journal of Health and Social Behavior 51(3): 307-324.

Marson, S. M. (2009). What do you say when a resident loses control? The Internet Journal of Geriatrics and Gerontology 4(2) Available on http://www.ispub.com/journal/the_internet_journal_of_geriatrics_and_ 
International Journal of Ageing and Later Life

gerontology/volume_4_number_2_55/article/what-do-you-say-when-aresident-loses-control.html (Accessed: September 16, 2011).

Marson, S. M. \& Della Fave, L. R. (1994). A Marxian review of gerontological literature. The Journal of Sociology and Social Welfare 21(3): 109-124.

McInnis-Dittrich, K. (2009). Social Work with Older Adults: A Biopsychosocial Approach to Assessment and Intervention. Boston, MA: Allyn \& Bacon.

Mitka, M. (2009). Worst nursing home. JAMA: Journal of the American Medical Association 302(18): 1960.

Mulder, J. D. (1987). Avoiding gerontophobia. Geriatrics 43(3): 96-97.

Nezu, A. M., Ronan, G. F., Meadows, E. A. \& McClure, K. S. (2000). Practitioner's Guide to Empirically Based Measures of Depression. New York: Kluwer Academic/Plenum.

NIMH (National Institute of Mental Health). (2011). Older Adults: Depression and Suicide Facts. Fact sheet. Available on http://www.nimh.nih. gov/health/publications/older-adults-depression-and-suicide-facts-factsheet/index.shtml (Accessed: October 15, 2011).

Nolan, P. D. \& Triplett, J. (2010). Sociology's suicide: A forensic autopsy? American Sociologist 41(3): 292-305.

Patten, P. C. \& Piercy, F. P. (1989). Dysfunctional isolation in the elderly: Increasing marital and family closeness through improved communication. Contemporary Family Therapy 11(2): 131-147.

Pedahzur, A. \& Perliger, A. (2003). Altruism and fatalism: The characteristics of palestinian suicide terrorists. Deviant Behavior: An Interdisciplinary Journal 24(3): 405-423.

Ploeg, J., Campbell, L., Denton, M. \& Joshi, A. (2004). Helping to build and rebuild secure lives and futures: Financial transfers from parents to adult children and grandchildren. Canadian Journal on Aging 21(S1): S131-S143.

Pridemore, W., Chamlin, M. \& Cochran, J. (2007). An interrupted timeseries analysis of Durkheim's social deregulation thesis: The case of Russian federation. Justice Quarterly 24(2): 271-290.

Putnam, R. D. (2000). Bowling Alone: The Collapse and Revival of American Community. New York: Simon \& Schuster.

Quadagno, J. (2011). Aging and The Life Course: An Introduction to Social Gerontology. New York: McGraw-Hill. 
Robinson, D., Renshaw, C., Okello, C., Moller, H. \& Davies, E. (2009). Suicide in cancer patients in Southeast England from 1996 to 2005: A population based study. British Journal of Cancer 101(1): 198-201.

Robinson, J. P., Shaver, P. R. \& Wrightsman, L. S. (1991). Measures of Personality and Social Psychological Attitudes. Volume I, San Diego, CA: Academic Press.

Sarkisian, N. \& Gerstel, N. (2008). Till marriage do us part: Adult children's relationships with their parents. Journal of Marriage and Family 14(4): 360-376.

Stuen, C. (2006). Older adults with age-related sensory loss ( $1^{\text {st }}$ edition). In B. Berkman \& S. D'Ambruoso (eds.), Handbook of Social Work in Health and Aging (pp. 65-67). Oxford: Oxford University Press.

Suominen, K., Henriksson, M., Isometsa, E., Conwell, Y., Heila, H. \& Lonnqvist, J. (2003). Nursing home suicides-a psychological autopsy study. International Journal of Geriatric Psychiatry 18(12): 1095-1101.

Thompson, P. (1999). The role of grandparents when parents part or die: Some reflections on the mythical decline of the extended family. Ageing and Society 19(4): 471-503.

Widrick, R. M. (2010). Age-related stigma and the golden section hypothesis. Aging and Mental Health 14(4): 375-385.

Wilson, K. G., Curran, D. \& McPherson, C. J. (2005). A burden to others: A common source of stress for the terminally ill. Cognitive Behavior Therapy 14(2): 115-123. 